\title{
Interpretation of the concept of "discount" in Technical Works Tenders
}

Pavlos, METALLINOS, School of Science and Technology, Hellenic Open University kpaulosm@netscape.net

\begin{abstract}
The text deals with the concept of the discount submitted by a candidate contractor tendering for a public works project. In accordance with prevailing conceptions, the quantity of the discount is perceived as being the amount of monetary compensation the candidate building contractor is willing to forgo for the sake of emerging as the winner of the tender. The text argues on the contrary that the discount is an objectively measurable magnitude. Specifically it is equal to the algebraic difference of the absolute surplus value that could be appropriated by the public works contractor minus the quantity of relative surplus value by virtue of which he is able to recoup the amount of discount submitted in the tender.
\end{abstract}

Keywords: Discount, Public Works, Surplus value, contract.

JEL Classification: H3, H4, P4.

\section{Introduction}

A crucial element, influencing and indeed determining the necessary prerequisites for reproduction of the capitalist mode of production, is the fixing by law of the length of the working day (MECW, 1996: p. 240-241 \& 415). Following the passage of such legal restrictions on working time, the generic entrepreneur is obliged to repurchase the use value of labour powerif he is to employ it once more (MECW, 1996: p. 241) for completing work already initiated or for carrying out the next step in the productive process. In any case, what he aims to do (MECW, 1996: p. 748, $749 \& 750$ ) is to ensure that his capital's total circulation is executed uninterrupted. This is what has prevailed to be defined as the reproduction of his capital.

Thus, if $X$ is the initially paid necessary money capital, with a view to starting the production process, we have the model 


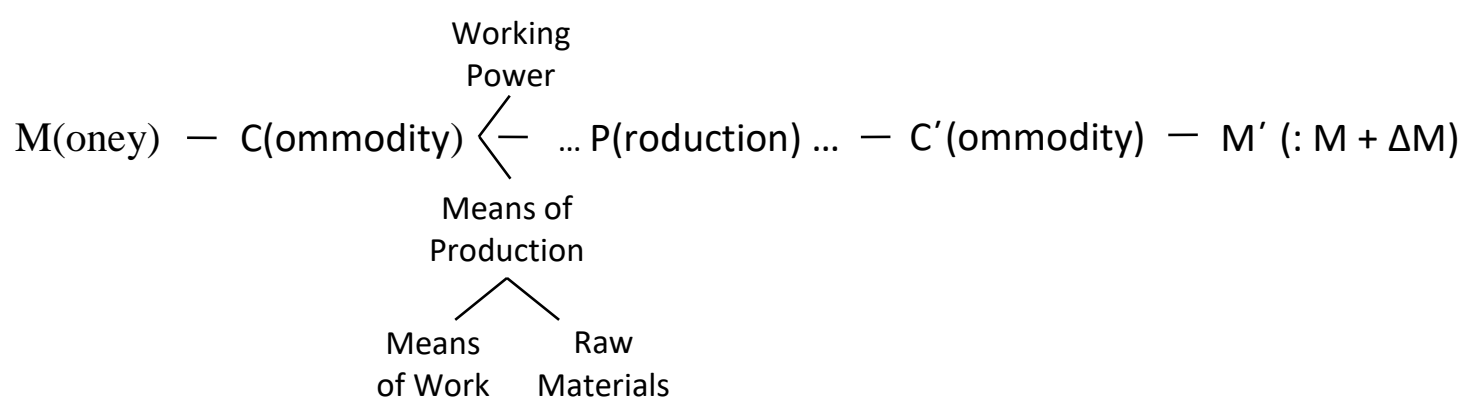

$$
M-C-\ldots P \ldots-C^{\prime}-M^{\prime}(M+\Delta M)
$$

which attributes the total circulation of capital (: production and circulation of commodity) entering the production process of an $\mathrm{E}^{\prime}$ commodity whose equivalent in money is equal to $X^{\prime}$, that is, this is equal to the initially paid capital in money $\mathrm{X}$, plus the equivalent in money $\Delta \mathrm{X}$ of spent surplus value.

That part of $\Delta \mathrm{X}$ which he does not consume it for his survival, the entrepreneur accumulates it (MECW, 1996: p. 161, 177-181, 203-206, 578-580 \& 619; MECW, 1997: p. 84-85, 342-343 \& 488-489) in order to secure the conditions for reproduction and expansion of his capital, fixed and variable.

\section{The Concepts of Surplus Value, Absolute Surplus Value and Relative Surplus Value}

The length of a working day $T_{\varepsilon}$ comprises two parameters:

- the time period $T_{\alpha}$, which corresponds to the period during that the necessary labour is being paid for and the equivalent of the exchange value is being produced for reproduction of the labour power of the worker as use value.

- the time period $T_{U}$, which corresponds to the period during which surplus labour is being expended and surplus value is being produced.

The relationship between $T_{\alpha}$ and $T_{u}$ is one of inverse proportionality to each other. But, in aggregate they are always equal to $T_{\varepsilon}$

$$
\mathrm{T}_{\alpha}+\mathrm{T}_{\mathrm{u}}=\mathrm{T}_{\varepsilon}
$$

To increase the quantity of surplus value appropriated, the generic entrepreneur is obliged to enlarge $T_{\varepsilon}$ so that there will be an increase in surpluslabour time $T_{v}$ and thus in the quantity of surplus value produced, assuming that 
the quantity of necessary labour remains stable and for this reason, also the time T remains stable. In this case, we have production of absolute surplus value.

Alternatively, it is possible for a larger quantity of surplus value to be produced within $T_{u}$ and/or for $T_{\alpha}$ to be reduced, with Tubeing increased by the same amount, without any change in their aggregate $T_{\varepsilon}\left({ }^{M E C W}, 1996:\right.$ p. 325-326 $\& 512$ ). In this case we would have production of relative surplus value (MECW, 1996: p. 320 \& 510-511).

With this in mind, it becomes understood why the above-mentioned establishment of a specific duration for the working day confining it within certain given time boundaries, obliges the producer-owner of the means of production to choose the latter option (MECW, 1996: p. 319-320). How would he manage this? By boosting the productive potential of his fixed and variable capital.

\section{Maximization of Relative Surplus Value}

It is obvious that maximization of the relative surplus value that is generated in the course of a productive process is predicated above all on reduction of the necessary labour time $\mathrm{T}_{\alpha}\left({ }^{\mathrm{MECW}}, 1996: \mathrm{p} .319-320\right)$. This is translated into reduction

- of the value of the commodities employed in use value reproduction of the working power

- or / even to reduction in the value of the means of production and raw materials used to produce these commodities which are used to reproduce the use value of labor power (MECW, 1996: p.: 320).

The producer's objective aim is to effect a reduction in the value of the commodities he produces, so that within the same period of time he is able to churn out more commodities. This fact is equivalent to maximization of the relative surplus value he appropriates (MECW, 1996: p.: 412-413 \& 325-326). Both the former prerequisite and the latter can be achieved only through an increase in the productive power of labour (MECW, 1996: p.: 326).

The enlargement of productivity creates specific conditions. These are the average level of skill of the workers, the degree of development of the science and technology of adaptability, the social division of labour, the volume and the efficacy of the means of production, the physical conditions (MECW 1991: p. 42) etc. Therefore, its achievement presupposes an overturn of the technical and social terms of the productive process (MECW, 1996: p.: 320). 


\section{Discount (x1)}

\subsection{Introduction}

Generally speaking, the concept discount may be rendered as an equivalent in money deducted from the initial budgeted cost $X_{1}$ of the project. We are led on this if we focus strictly on the moment when the buyer is negotiating with the would-be construction contractors (the tendering).

In particular, in accordance with international practice and with regard to the object of public works sector, in order the public authority put at an auction the project, it performs a pre-auction procedure by which it calculates the algebraic price $X_{1}$ of the estimated cost of construction.

Furthermore, with regard to Greek practice in particular (Metallinos, 2011a), the collective capitalist obliges the designer of a public project to include and determine the algebraic price $T_{2}$ of the necessary construction time for the execution of the project's production. $T_{2}$ corresponds to the time needed for construction of the same technical commodity using the same technology, division of labour, expertise, etc. when the buyer is not the public sector but a private person. One necessary prerequisite for the project being put up for tender is thus designation of the dyad $\left(\mathrm{X}_{1}, \mathrm{~T}_{2}\right)$. Because $\mathrm{T}_{2}$ acquires legal status, the contractor of the project is now bound, as $T_{2}$ is included in the contract. The logic is simple. As far as the construction technology is concerned, objectively it is accepted that in the end, this is the same whether the ordering person is a public authority or a private individual. Thus, it is assumed that for its production the same amount of time is required which would be required if it were being manufactured on behalf of an individual. Therefore, from his own experience, one can estimate the size of the above-mentioned $T_{2}$ value. However, only on the $X_{1}$ price, the candidate manufacturers submit their tenders.

Thus, for the calculation of the starting cost $\mathrm{X}_{1}$, with regard to the Greek mode of production and execution of public works, the public authority uses the Public Works Ministry's institutionalized Lists. Construction works of all kinds are included in them. Under Greek legislation,

(i) up to mid-2004, these Lists were compiled and the cost of each work had been calculated in accordance with the method of so-called "Prices Analysis", which in practice were taking into account the theoretical background of the functional analysis.

(ii) since 2004, these Lists were updated related to implemented technology, contemporary specifications, etc. However, their costs were 
arbitrarily determined, according to the legislator's judgment, unlike previous practice.

From the abovementioned lists of either the first (i) or the second indent (ii), under Greek law, the public authority which wish to ascertain the cost of a public works project $\mathrm{X}_{1}$, has to select the tasks that are prescribed as necessary on the basis of scientific engineering criteria for a technical study to be carried out and the project constructed. The specific aggregate of tasks selected from the lists is called the project Invoice. Subsequently, with assistance from the project Invoice and pre-measured quantities of work and materials, the Budget for the project is compiled. The result of the algebraic calculations gives the price of the Budget $X_{1}$, which corresponds to the estimated construction cost.

In particular, with regard to the facts of case (i), it emerges that through the works included in the project's Invoice and the pre-measured quantities of them and raw materials, in an ideal case, the completion time for the project could be estimated equal to the algebraic price $T_{1}$, even before commencement of construction work on the project. Of course in practice this could have been feasible if we knew the technical composition of the capital, the mode of distribution of technical tasks, the productivity, etc. of the contracting construction capital, which would become evident in the course of the tendering for the construction project. Nevertheless, $T_{1}$ cannot be ignored, even though it is an hypothetical parameter, as it turns out. It is noted that the conceptual difference between $T_{1}$ and $T_{2}$ is focused on the fact that $T_{2}$ tends closer to the time required to produce the project, taking into account the experience of the construction site. Conversely, $T_{1}$ is completely theoretical, an abstract concept, since it only takes into account the theoretical background of functional analysis, even if it could be calculated. For this reason, it worths $T_{2} \leq T_{1}$.

Under Greek legislation the candidate contractor tendering for the project is therefore required - above and beyond the technical subject matter of the study - to accept imposition by the state of the dyad $\left(X_{1}, T_{2}\right)$ as a parameter in the specific tendering. He will submit his tender on the price $X_{1}$. In addition, his submission will commit him to constructing the technical project in the time period $T_{2}$. In short, these are the crucial parameters $\left(X_{1}, T_{2}\right)$, that are taken into consideration by every candidate contractor, quite apart from the objective scientific technical application, when he makes the $X^{*}{ }_{1}$ offer during the tendering. 


\subsection{Public Works Tendering}

When the tendering process is completed and the contractor selected, prior to commencement of the construction works, the abovementioned dyad $\left(X_{1}, T_{2}\right)$ is assigned its final price : $\left(X_{1}^{*}, T_{2}\right)$.

In accordance with paragraphs 2 and 3 of the text, the conclusion from the abovementioned is that the consultant's intervention to reduce the time from hypothetical $T_{1}$ to realistic $T_{2}$, could be the equivalent of a mechanism for active reduction of production time by such a quantity of absolute surplus value time as the generic contractor could, as an individual, appropriate as relative surplus value. It is in this manner that the state makes a preliminary selection for the purpose of singling out the contractor best equipped to undertake construction of the project in question.

This is moreover the reason why the contractor is punished if he does not succeed in delivering the product to its users within the time interval $T_{2}$, despite the commitment undertaken both by virtue of participation in the tendering and under the terms of the agreement jointly signed with the public authority that has put at an auction the project.

The formula to be applied is therefore as follows:

$T_{1}-T_{2}=t^{*}$, absolute surplus value time

\section{Conclusions}

The more intense the competition between the "aspirants" the more they depreciate, by amounts $x_{1}$, the the cost of auctioning budget $X_{1}$. This may be attributed to the extent of the trust that each one of them has in his constructual ability, and in particular the increasing productivity of his capital, the high standard of his technical division of labor, etc. in relation to his competitors. Judging from what was mentioned above in the text, they aim to recoup the amount of absolute surplus they are prepared to sacrifice by obtaining the quantity of relative surplus value that is ensured for them by virtue of their general way of working.

The maximum discount figure $x_{1}$ is equal to the maximum amount of relative surplus value that can be appropriated by the contractor on the strength of his capital's productivity, the technical division of labour in his work, his expertise, etc. 
Thus, because the following applies (Metallinos, 2011b):

$$
\begin{aligned}
& \begin{array}{l}
\mathrm{X}^{*}{ }_{1}=\mathrm{X}_{2}+\mathrm{x}^{*}{ }_{1} \\
\mathrm{X}^{*}{ }_{1}=\mathrm{X}_{1}-\mathrm{x}_{1}
\end{array} \\
& \begin{array}{c}
\mathrm{X}_{2}+\mathrm{x}^{*}{ }_{1}=\mathrm{X}_{1}-\mathrm{x}_{1} \\
\mathrm{t}^{*}{ }_{1}+\mathrm{t}_{1}=\mathrm{T}_{1}-\mathrm{T}_{2}
\end{array} \\
& \rightarrow \\
& \mathrm{x}^{*}{ }_{1}+\mathrm{x}_{1}=\mathrm{X}_{1}-\mathrm{X}_{2}
\end{aligned}
$$

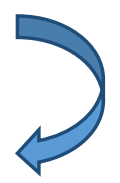

it is to be concluded that an equivalent in money $\mathrm{x}^{*}{ }_{1}$ is generated, as a structural characteristic of the overall circulation of the commodity in Greece known as the public works project. This equivalent in money is corresponded to the absolute surplus value, which is appropriated a priori by the contractor, during the exploitation's time period $\mathrm{t}^{*}{ }_{1}$ of the working power. This equivalent in money is not appropriated as a result of any increase in the productivity of his work or of the technical division of his capital's labour but as an outcome of the process of negotiation (tendering) of the terms of exchange between public work project's buyer and seller. The specific quantity of absolute surplus value is not confirmable empirically when the transaction is conducted between private individuals. It can be appropriated by the contractor only if he has collaborated with the public sector in construction of the specific (on each occasion) project. On the contrary, he does not appropriate it if the buyer is a private citizen rather than a public body. 


\section{References}

[1] Marx K., Commodity and Money, 42, Kritiki editions, Athens 1991.

[2] MECW, vol. 35, K. Marx, Capital-vol.1, ed. Lawrence \& Wishart, 1996

[3] MECW, vol. 36, K. Marx, Capital-vol.2, ed. Lawrence \& Wishart, 1997

[4] Metallinos P. (a), "Application of Mathematical Method in Public Works Tendering in Greece", European Journal of Law and Economics(Article No. 9256), Springer 2011.

[5] Metallinos P. (b), Public Works Management - costing policies and legislative study, Tziola editions, Thessaloniki 2011. 